\title{
O simulacro da Rainha: performance, ritual e corpo no Reisado Santa Helena
}

The simulation of the Queen: performance, ritual and body in the Reisado St. Helena

Ribamar José de Oliveira Junior ${ }^{*}$

* Universidade Federal do Rio de Janeiro - Rio de Janeiro, RJ, Brasil Doutorando em Comunicação e Cultura ribamar@ufrj.br https://orcid.org/0000-0002-5607-2818

\section{Lore Fortes ${ }^{*}$}

** Universidade Federal do Rio Grande do Norte - Natal, RN, Brasil lorefortes4@gmail.com https://orcid.org/0000-0003-0046-7359 


\title{
Resumo
}

Este artigo apresenta uma reflexão antropológica para a performance de Francisca da Silva, mais conhecida como Tica, brincante da tradição cultural do Reisado no figural de Rainha no grupo Santa Helena em Juazeiro do Norte, interior do Ceará. O interesse consiste em perceber a forma com que Tica produz a dissidência sexual e de gênero por meio do uso do corpo na repetição da performatividade feminina, sobretudo na forma de inventar a existência social a partir dos eixos de precariedade e de vulnerabilidade. Ao trazer a manifestação popular religiosa do Reisado, procuramos perceber como a noção de teatro como encantamento aparece no momento em que Tica incorpora a Rainha no rito, principalmente do ponto de vista da majestade no corpo da brincante que dignifica a vida comum a partir da expansão criativa e política da dança no contexto subversivo da imitação.

Palavras-chave: cultura popular; gênero; performance; Reisado.

\begin{abstract}
This article presents an anthropological reflection for the performance of Francisca da Silva, better known as Tica, who plays the cultural tradition of the Reisado in the figural of Queen in the Santa Helena group in Juazeiro do Norte, in the interior of Ceará. The interest is to perceive the way in which Tica produces sexual and gender dissidence through the use of the body in the repetition of female performativity and is therefore a way of inventing social existence from the axes of precariousness and vulnerability. In bringing the popular religious manifestation of the Reisado, We try to perceive how the notion of theater as enchantment appears at the moment when Tica incorporates the Queen in the rite, mainly, from the point of view of critical power that the majesty of the giver dignifies the common life from the creative expansion and dance politics in the subversive context of imitation.
\end{abstract}

Keywords: popular culture; gender; performance; Reisado. 


\section{Introdução}

Com uma estrela de pérolas brancas no meio da testa, a coroa do figural ${ }^{1}$ de Rainha enfeita a cabeça de Francisca da Silva, mais conhecida como Tica, que vestida de noiva se prepara para cortejo de Reisado em Juazeiro do Norte, interior do Ceará. O festejo natalino, chamado de Ciclo de Reis, geralmente ocorre no município da segunda quinzena de novembro à primeira quinzena de janeiro do ano seguinte. Segurando um retrovisor de uma motocicleta, a brincante ${ }^{2}$ do grupo Santa Helena se olha e pede para que o primeiro autor escolha um dos anéis que ela irá utilizar na performance daquele dia de Reis, 8 de janeiro de 2018. Tica coloca o anel verde no dedo anelar da mão esquerda e espera 0 ônibus chegar para transportar os demais brincantes do grupo do bairro Frei Damião para o centro da cidade. O percurso dançado começa na Praça da Prefeitura e segue até a Praça Padre Cícero ao som de zabumba, rezas e cantorias.

A cena descrita aparece entre o período de outubro de 2016 a março de 2019, no qual conversamos com Francisca da Silva, mais conhecida como Tica, Rainha na tradição religiosa do Reisado em Juazeiro do Norte. No período em que se iniciou a pesquisa, ela morava no bairro Frei Damião, ao lado da casa de José Amaro da Silva, mais conhecido como Mestre Dedé, dono do Boi, ou seja, proprietário mestre do grupo Santa Helena. Atualmente, Tica mora no bairro Timbaúbas em uma casa azul com o companheiro Cícero, embaixador ${ }^{3}$ do grupo de Dedé. O encontro começou após a apuração de uma pauta jornalística da $3^{\mathrm{a}}$ edição do Jornal Sertão Transviado ${ }^{4}$ mídia impressa experimental elaborada durante a vigência do projeto "Sertão transviado: outros Cariris", vinculado às Pró-Reitorias de Extensão e de Cultura da Universidade Federal do Cariri (UFCA), nos anos de 2016 a 2018. O jornal teve como linha editorial os entrelaçamentos entre gênero e sexualidades diante da cultura popular na região do Cariri, sobretudo na visibilidade e na dizibilidade das paisagens transviadas,

1 De acordo com a narrativa do Reisado e o linguajar popular, a palavra "figural" está associada à noção de personagem, incorporado durante a performance cênica da dança.

2 Termo utilizado para nomear pessoas que dançam Reisado a partir da noção de que a tradição religiosa é um brinquedo sagrado, como menciona Barroso (2017).

3 O "embaixador" é umas figuras que compõe os cordões do Reisado, ou seja, que está presente no formato do cortejo, colocado entre duas fileiras de até seis brincantes em cena.

4 Edições disponíveis para leitura digital em: https://issuu.com/sertaotransviado. 
como sugere o conceito de Bento (2017) que propõe uma releitura brasileira do queer, no sul do Ceará.

O objetivo inicial era produzir uma entrevista com Tica a fim de elaborar um perfil para a edição do impresso, porém após a condução da pauta surgiu o interesse de acompanhar as práticas da brincante durante as performances do grupo Santa Helena e as suas execuções cotidianas da performatividade de gênero, ${ }^{5}$ nas explanações de Butler (2016). A performance aparecia como ponto privilegiado para entender o simulacro da Rainha na incorporação de Tica na mesma medida em que a cotidianidade da brincante surgia como fio condutor de uma trajetória marcada pelas condições de precariedade e de vulnerabilidade. A pesquisa pretendeu acompanhar os ensejos para o rito e para os atos que envolvem tanto os preparativos como também a reprodução do corpo para a dança.

Era uma tarde do dia 5 de outubro de 2017. Após três batidas na porta da casa de Dedé, ele abre e explica que Tica havia saído para trabalhar com a carroça coletando materiais recicláveis para o sustento. A rua não possuía calçamento, nem saneamento básico. Josefa da Silva, mais conhecida como Zefinha, matriarca do grupo por ser a mulher mais velha do Reisado, segura na costela direita o filho mais novo de Dedé, que, chupando a chupeta, encara a lente da câmera pendurada no pescoço do primeiro autor.

Retornamos à tarde naquele mesmo dia. A porta da casa de Tica já estava aberta, um cachorro estava deitado na calçada e a burra Nina, transporte do casal, descansava comendo capim. Antes de pedir para entrarmos, Tica pediu desculpas. Lamentou o fato de estar trabalhando tanto e de não ter nos recebido na hora correta. De dentro, Cícero grita sem saber que tem visita na sala de estar. A sala é pequena, na parede quadros tamanho 10x15 de imagens de santos populares, dos familiares e da pintura vernácula do Sagrado Coração de Jesus. Com um rosário pendurado no pescoço, uma blusa cor-de-rosa e uma saia preta com rajadas brancas, Tica cruza as pernas e fala seu nome, conforme está no registro oficial: Francisco da Silva.

5 Segundo a autora, "performatividade não é um jogo livre nem uma autoapresentação teatral; não pode também ser igualada à performance. Além disso, a regulação não é necessariamente aquilo que coloca um limite à performatividade, a regulação é, ao contrário, aquilo que impele e sustenta a performatividade" (Butler, 1993 p. 93, tradução nossa). 
Não demora muito para Tica explicar que "nasceu de papo para cima". 6 A parteira quando viu que o menino, assim lido pela heteronorma, da falecida Tereza havia vindo ao mundo como tal, anunciou de antemão que ele ia ser mais mulher do que homem, nas palavras de Tica. Porém, isso não aparece como argumento suficiente para Tica querer mudar os nomes ou fazer uma modificação corporal. Desse modo, Tica considera que é "mais feminina do que masculino", "pois de acordo com a visão da parteira, antes da leitura do discurso médico, o bebê que nasce de papo para cima, tradicionalmente é mulher, e o bebê que nasce de papo para baixo ou emborcado, é tradicionalmente homem" (Oliveira Junior, 2019, p. 7). Devota de São Francisco, santo que deu origem ao seu nome, ela nunca casou na Igreja, mas conta que se apaixonou por Cícero nos cordões ${ }^{7}$ do Reisado. O convite para participar do grupo foi por meio de Zefinha, que, apesar de não ser a dona do Boi, pela memória que não abarca as toadas cantadas, dá o espaço para o filho cantar, Dedé.

Em 2015, pela primeira vez, Tica ocupa um figural tido como feminino. Sai no cortejo do Reisado Santa Helena como Rainha, sob autorização do Mestre Dedé. O Mestre explica que o "jeito" da brincante não desfez a beleza e a majestade da Rainha. Desse modo, é possível perceber nas mediações da cultura popular da região do Cariri cearense a presença subversiva da performance na produção de sentido na cultura. Como Rainha, Tica alcança uma poética que afirma um novo olhar sobre o que seja considerado tradicional através de uma complexa relação entre a prática do Reisado e os artivismos das dissidências sexuais e de gênero que, segundo Colling (2018, p. 162), "entendem que as identidades são fluidas e que novas identidades são e podem ser criadas, recriadas e subvertidas permanentemente".

Nesses termos, o interesse da pesquisa consiste em perceber o contexto em que Tica produz a dissidência sexual e de gênero por meio do uso do corpo na repetição da performatividade feminina, sendo essa forma uma maneira de inventar a existência social a partir dos eixos de precariedade e de vulnerabilidade. Ao trazer a manifestação popular religiosa do Reisado, procuramos

6 Expressão popular para designar a posição de cabeça para cima, exatamente o inverso da posição do corpo de bruços.

7 Como é chamada a organização dos brincantes em cena de acordo com o formato do cortejo em apresentação. 
perceber como a noção de teatro como encantamento aparece no momento em que Tica incorpora a Rainha no rito, principalmente do ponto de vista da potência da majestade do figural que dignifica a vida comum a partir da expansão criativa e política da dança no contexto subversivo da imitação.

A pesquisa etnográfica, nos moldes de Pereira (2012), começou com Tica, no momento em que, após nove meses do exercício do ofício antropológico (Oliveira, 1988) diante das idas a campo, das entrevistas semiestruturadas e das observações do cotidiano, a brincante para e pergunta sobre a sexualidade do primeiro autor, mais especificadamente, se ele era "mona", como ela. O ocorrido do dia 9 de julho de 2017 na sala de estar de Tica, contou muito sobre alteridade, como menciona Goldman (2006), na prática antropológica e contribuiu positivamente para a etnografia das práticas que envolviam a visibilidade da experiência LGBTQ $+^{8}$ na cultura popular cearense.

Esta pesquisa etnográfica procura afirmar, como destacam Rohden, Russo e Roca (2017), a possibilidade de fronteiras fluidas e porosas contra a fixidez do essencialismo na cultura popular, sobretudo nos estudos de gênero e sexual a partir dos artivismos das dissidências na cultura, sendo o conceito de Colling (2018, p. 161) importante para perceber que "os preconceitos nascem na cultura e que a estratégia da sensibilização via manifestações culturais é mais produtiva”.

Assim, acreditamos que o figural de Rainha oferece um artifício para se pensar a produção de saberes desterritorializados em intervenção com a produção do corpo nas invenções das tradições culturais. Uma vez que, "à medida que alguém se torna aquilo em que se torna, elx muda tanto quanto elx próprix" (Pereira, 2017, p. 158). Ao considerar que "a pesquisa de campo não tem momento certo para começar e acabar" (Peirano, 2014, p. 379), visamos acompanhar os momentos específicos durante o percurso etnográfico sobre a vivência de Tica para refletir sobre o simulacro da Rainha na performance da brincante. No sentido de discutir as relações entre drama social e drama estético de Tica, o diagrama de Schechner (1976), visto como um oito deitado em que na ponta de cada laço do número estão situados o drama social e o drama estético, oferece um ponto de partida para a análise.

8 LGBTQ+ é a sigla de Lésbicas, Gays, Bissexuais, Travestis, Transexuais ou Transgêneros e Queers. O sinal positivo pretende alcançar as dinâmicas de gênero e sexualidade a partir das disparidades que Colling (2015) pontua entre o movimento LGBT e os ativismos queer. 


\section{Performance e ritual: o simulacro da Rainha}

Quase todos os Reisados se apresentam no cortejo que simula as caminhadas de guerreiros ou peregrinos, influenciados pelas profecias e pelos heróis. "Em todos os casos, trata-se de um grupo em travessia, cuja origem e destino são desconhecidos pelo público e não vividos pelos brincantes" (Barroso, 2013, p. 109). O gesto performativo da Abrição de Portas, segundo o autor, anuncia o rito de criação capaz de delinear a esfera sagrada pela licença pedida para adentrar a casa. Nas cidades são utilizados quadras, praças e salões para se dançar. Os bailes representam as danças ou as coreografias, após o baile o primeiro entremeio a ser puxado pelo mestre é o Boi.

$\mathrm{O}$ autor traz que o Boi é feito de maneira artesanal; tradicionalmente, sua armação ocorre com arcos de varas flexíveis que retratam as costelas do bicho, chamado de Boi de Costela ou de Vara. No caso dos Reisados de Congo, o entremeio ganha nome de Boi de Junta pelo fato de que é um brincante que incorpora o bicho, entrando dentro dele. Os enfeites do Boi estão a critério de cada grupo. No decorrer da cena do entremeio, são variados os procedimentos que vão do levantamento do Boi até a sua morte, as peças são puxadas e cada cena é elaborada pelos brincantes com o objetivo de ressuscitar o animal. Já a Burrinha está mais associada ao folguedo de forma lírica e feminina, conforme o autor, o bicho vem preso no corpo do brincante com material de madeira. O entremeio aparece conduzido por um rapaz vestido de menina com uma saia colorida e blusa de mangas compridas.

Dentro da performance são diversas as cantorias, elas aparecem dispostas entre as peças, os repentes, os relaxos, as loas e as loudaças. ${ }^{9}$ Tradicionalmente, as peças versam sobre temas diversos e revelam o caráter improvisado da cena. Os repentes representam versos improvisados sobre "questões sérias, como problemas sociais, religioso, políticos, econômicos e etc." (Barroso, 2013, p. 270). Os relaxos são cômicos e invertem os valores sociais em disputas improvisadas, o autor percebe que muitas vezes essas cantorias trazem uma visão negativa e discriminatória com as mulheres. As loas são direcionadas a pessoas respeitadas e entes queridos, destacam em louvores e devoção cumprimentos

9 Esses tipos de cantorias adquirem um caráter cômico nas apresentações na mesma forma de reverência a alguém durante a encenação do Reisado. 
formalizados, enquanto as loudaças adquirem um caráter cômico nas apresentações na mesma forma de reverência a alguém.

Barroso (2013) define a performance cênica do Reisado entre um gestual singular e acrobático, destaca que muitas vezes as cenas são encorpadas pelos brincantes e mestres que possuem quase 70 anos da idade. Os atores-dançarinos no folguedo desempenham "movimentos preestabelecidos, executados por corpos preparados, que incorporam procedimentos artísticos e cotidianos, característicos do que a antropologia teatral considera ser o ator performático" (Barroso, 2013, p. 306). Segundo o autor, a contribuição pessoal da dança, recebida pelos gestos, vozes e movimentos da tradição, revela a inclusão de novos signos e a recriação de enredos, evidenciados pela forma com que se observa e se capta a transmissão oral. Diante do talento individual do brincante é possível perceber que há a adaptação da dança com a flexibilidade necessária do lugar e do momento.

Bois e Reisados utilizam formas cênicas características das sociedades tradicionais, nas quais prevalece o espírito religioso, a visão sagrada do universo e onde o mundo preserva o seu encanto. Originam-se de ambientes onde o homem e natureza, arte e vida, ainda não estão todo apartados. Como expressões de culturas orais, utilizam linguagens mito-poéticas que, muitas vezes, não privilegiam a palavra no processo de comunicação. (Barroso, 2013, p. 307).

A cosmologia da tradição não só aparece assentada no pensamento mágico, como também atesta as formas do fenômeno teatral. No processo de criação artística, o autor aparta que o Reisado se apoia em matrizes tradicionais para desempenhar a construção de situações dramáticas com base no improviso, entre o público e os brincantes, através da ritualização de códigos sistematizados no corpo e na fala, principalmente na criação de arquétipos pautados pelo imaginário coletivo.

Desse modo, o "percurso do cortejo performático aparece permeado por processos de aprendizagens do corpo, ainda mais de forma subversiva, quando $o$ corpo aparece marcado pela dissidência na releitura de uma possível tradição transviada" (Oliveira; Fortes, 2018, p. 59-60). Ao levar em consideração as narrativas do cortejo, evidencia-se a relação de gênero e sexualidade a partir do símbolo ritual na performance cênica da Rainha e da experiência de Tica. 
Em um primeiro momento, percebemos a performance cênica do Reisado como um rito de passagem que aparece entre os fenômenos liminares e liminoides, ritos e brincadeiras, como explica Turner (2012). Quando Barroso (2017) considera o Reisado um brinquedo sagrado, o autor destaca que o brincante possui o dom de brincar, percebido por um mestre e aprimorado pela dança. Diante das definições de Turner (2012) sobre liminar e liminoide, percebemos que o tempo que o brincante leva para aprender a dança de Reisado está na fase liminar, na medida em que elabora o saber do corpo nos terreiros na preparação para o rito, e a performance cênica da brincadeira está no liminoide, quando o brincante esboça a seriedade do rito religioso na brincadeira de Reis.

No sentido de discutir as relações entre drama social e drama estético de Tica, o diagrama de Schechner (1976) oferece um ponto de partida para a análise da performance da Rainha do Reisado Santa Helena. É importante destacar que o drama social aparece como "a unidade empírica do processo social onde derivaram e continuam a derivar os variados gêneros da performance cultural" (Turner, 1987, p. 92, tradução nossa). Nesse sentido, consideramos que o vestido branco da Rainha, no grupo do Mestre Dedé, aparece como um símbolo ritual que proporciona a ação em cena da personagem de Tica "como um potencial criador ou inovador da ação humana" (Turner, 2012, p. 214). É como se, durante o cortejo de Reisado, o figural da Rainha tanto ganhasse como perdesse significado quando incorporado por Tica, pois a produção de performatividade de gênero da brincante perpassa o rito mediado pelo improviso. Assim, observamos o envolvimento total de Tica na posição de Rainha.

Para tanto, partimos da noção de Turner (1982) sobre a performance completar uma experiência. No caso de Tica, consideramos a hipótese de que durante a performance, dentro do vestido branco da Rainha, tida como um figural feminino do Reisado, a brincante significa a experiência como mulher transexual. Pois é o momento em que a enunciação descritiva do corpo de Tica pela parteira, como feminino por ter nascido de papo para cima, aparece evidenciada na enunciação performativa com a experiência na cultura popular através da feminilidade da personagem da Rainha do Reisado. "O significado surge quando tentamos associar o que a cultura e a língua cristalizaram a partir do passado com o que sentimentos, desejamos e pensamos em relação ao instante presente da vida" (Turner, 2005, p. 177). 
Desse modo, esta etnografia se encaixa em uma das sete áreas que Schechner (1973) descreveu sobre a teoria da performance, no caso, na análise da performance da vida cotidiana de Tica e a sua relação com as reuniões do Reisado. Podemos dizer que a mera experiência de Tica se torna "uma experiência" a partir do momento em que ela é nomeada Rainha pelo Mestre Dedé. Pois "a mera experiência é, simplesmente, a passiva resignação e aceitação dos eventos" (Turner, 2005, p. 178). Ocupar um figural feminino dentro do Reisado aparece como uma experiência formativa e transformativa, ou seja, "sequências distinguíveis de eventos externos e de reações internas a eles tais como iniciação em novos modelos de vida" (Turner, 2005, p. 179).

No primeiro dia em que Tica saiu de Rainha, em 2015, ela conta que durante a performance ela não sabe as pessoas a viam como homem ou como mulher, mas, para ela, o mais importante era brincar. Logo, percebemos que ocupar o posto de Rainha do Mestre Dedé era para Tica a necessidade de "encontrar significado naquilo que se apresentou de modo desconcertante, seja através da dor ou do prazer, e que converteu a mera experiência em uma experiência" (Turner, 2005, p. 179). Assim, como explicitado em Oliveira Junior (2019), a fala de Zefinha que reconhece o gênero e a sexualidade de Tica a partir do modo como ela apresenta, aparece diante de uma diretriz significativa que emerge da subjetividade como brincante, tanto da matriarca do grupo como da brincante.

Pois se para Turner (2005) é irrelevante que o passado revivido pelo presente, tempo entendido pela duração da performance cênica do Reisado, seja "real" ou "mítico", consideramos que a ficção da Rainha em Tica proporcionou um ritual de passagem do corpo de Tica do estado de abjeção para o espaço político. Quando Zefinha diz que convidou a brincante para o Reisado em um momento de crise vivido por Tica, a matriarca usa uma frase que relembra a sororidade entre as mulheres: "Ela é mulher assim como eu." Assim, é possível destacarmos a processualidade do drama social diante das relações de gênero e sexualidade e a relação com o drama estético na performance tradicional.

Do teatro ao ritual, é como se no drama social de Tica primeiramente ela violasse uma norma estabelecida e socialmente aceita, destacada no fato de Tica ser uma mulher que nasceu com pênis e de "papo para cima"; em seguida, houve uma crise ao adentrar os grupos de Reisado e ocupar figurais masculinos, como embaixador; e, a partir da crise um processo de negociação ocorresse no Santa Helena, quando Tica pede para ser Rainha, e Dedé, ao reconhecer 
o gênero dela na forma como ela apresenta, houvesse uma reintegração, "a qual envolve o ajustamento a uma situação cultural original quanto o reconhecimento da permanência do cisma" (Carlson, 2011, p. 167). Como destaca Dedé, Tica ficou muito bonita como Rainha "na forma como ela é". Do ritual ao teatro, ao acompanhar os movimentos da vida social de Tica dentro do Reisado, percebemos que o drama social da brincante suscita os cinco momentos da "experiência vivida", definidos por Turner (1982).

Daí a importância dos dramas sociais, e dos rituais que os suscitam (através de rupturas socialmente instituídas) ou deles emergem (como expressões de uma ação reparadora). No espelho mágico dos rituais, onde elementos do cotidiano se reconfiguram, recriam-se universos sociais e simbólicos. (Dawsey, 2006a, p. 18).

No primeiro, a brincante ocupa o figural de Rainha, algo acontece na percepção dela e no grupo de Reisado; no segundo, a experiência do passado, a noção de que ela "seria mais feminina do que masculino", é evocada e delineada pela incorporação da Rainha; no terceiro, as emoções dos eventos passados podem ser revividas pela forma como a memória aparece no saber corporal da brincante, na medida em que Tica aprimora o corpo em uma produção de performatividade tida como feminina na esfera da teatralidade do gênero, como aponta Butler (2016); no quarto, o enunciado performativo da parteira diante do corpo de Tica encontra uma relação na construção do significado de Rainha; no quinto, Tica expressa o seu gênero feminino na feminilidade da Rainha e, por assim dizer, a experiência da brincante parece se completar como vivida por meio da arte performativa do Reisado. Desse modo, “Turner comenta que o ritual e as artes performativas derivam do cerne ("coração") liminar do drama social" (Dawsey, 2006a, p. 20).

Assim, o Reisado proporciona na condição de brincante uma fonte de poder liminar e o figural de Rainha detém na produção performativa do corpo de Tica uma forma liminoide. Dawsey (2006a) destaca duas características das formas liminoides, a primeira é de que elas ocorrem nas margens, ou seja, distantes da centralidade dos processos sociais e isso pode estar associado aos arranjos da heteronormatividade no campo da tradição da cultura popular; e a segunda é que além de ser mais criativas, podem também ser subversivas e, assim, destacamos a forma com que os saberes populares, tanto da parteira como do Mestre Dedé, legitimam o corpo de Tica como um corpo possível e legível. 
Experiências de liminaridade podem suscitar efeitos de estranhamento em relação ao cotidiano. Enquanto expressões de experiências desse tipo, performances rituais e estéticas provocam mais do que um simples espelhamento do real. Instaura-se, nesses momentos, um modo subjuntivo ("como se") de situar-se em relação ao mundo, provocando fissuras, iluminando as dimensões de ficção do real-f(r)iccionando-o, poder-se-ia dizer - revelando a sua inacababilidade e subvertendo os efeitos de realidade de um mundo visto no modo indicativo, não como paisagem movente, carregada de possibilidades, mas simplesmente como é. Performance não produz um mero espelhamento. (Dawsey, 2006b, p. 136, grifo do autor).

Em uma das canções do Reisado, momentos iniciais do rito de abertura de portas, chamado pelo Mestre Dedé de "abrição de portas", há a cantoria de uma peça em que um dos versos diz "entramos nesta nobre sala". Assim, pode-se dizer que uma mulher transexual dentro de um grupo de tradição, ao entrar em uma sala e dançar em uma praça pública, abre estratos mais amplos da vida social a partir do direito de aparecer e da esfera visível do gênero. O momento em que Tica não sabe se as pessoas a veem como homem ou como mulher é o momento que Dawsey (2005, p. 167) sugere como o de repensar o lugar olhado (e ouvido) das coisas, onde "estruturas decompõem-se - às vezes, com efeitos lúdicos. O riso faz estremecer as duras superfícies da vida social". A noção de riso do brincante de Barroso (2017) se associa de noção de liminoide da brincadeira de Turner (2012), pois as formas sérias do rito brincam gêneros, por assim dizer.

Parece ser no espelho da antiestrutura, como sugere Turner (1969), que a Rainha reverte relações de poder e rejeita a abjeção do corpo por meio da experiência liminar no Reisado e do límen do drama social de Tica. É nesse ponto que o vestido do figural ganha a conotação de símbolo ritual poderoso na incorporação da brincante. "Inversamente, personagens estruturalmente frágeis transformam-se em seres de extraordinário poder" (Turner, 1969, p. 94-130, tradução nossa). A antiestrutura se aproxima do que Barroso (2013) aborda como teatro encantado do Reisado, principalmente quando o autor menciona que o encantamento ocorre quando o brincante entra em cena e dignifica a vida comum no imaginário popular da majestade, e o desencantamento, quando o brincante sai de cena e retorna ao cotidiano. 
Portanto, pode-se dizer que a Rainha ao ser incorporada por Tica perpassa o efeito do espelho mágico e, em estado performático, proporciona ruídos nos quilombos a partir da tensão carregada entre os corpos. "Entidades ambíguas ou anômalas, consideradas como sendo estruturalmente perigosas, energizam circuitos de comunicação atrofiados. Abrem-se passagens em sistemas classificatórios estáticos. Surgem áreas de contágio. Espaços híbridos" (Dawsey, 2005, p. 166). Assim, o drama social de Tica, do rito ao teatro e do teatro ao rito, dentro do diagrama proposto de Schechner (1976), se relaciona com o drama estético da Rainha na medida em que a brincante, enunciada performativamente pela parteira e pelo Mestre Dedé, "usa as ações da vida social como matéria-prima para a produção do drama estético" e a Rainha pode representar a utilização "das ações tiradas do teatro como modelos para subsequentes ações sociais" (Carlson, 2011, p. 185). Esse movimento entre Tica e Rainha parece, como aponta Turner (1982), mais cíclico do que linear.

Portanto, cabe dizermos que a forma com que Tica sai do espaço da abjeção pela transexualidade perpassa um símbolo, vestido de Rainha, que "vincula ao grupo e elabora a ligação do sujeito com a sua própria experiência, e por isso ele pode transformar" (Cavalcanti, 2013, p. 422). O Reisado proporciona a liminaridade como rito pela experiência em communitas, ao inverter os papeis sociais, e a Rainha agencia pelo símbolo ritual a eficácia da reprodução performativa do gênero de Tica, e pode ser considerada o ponto de chegada da performance até a experiência social da brincante. Podemos dizer que Tica "contraproduz", nos termos de Preciado (2004), a tradição por meio da antiestrutura no Reisado.

\section{Brincadeira de gênero na Rainha do Reisado Santa Helena}

Nesse sentido, a contrassexualidade de Preciado (2004) não seria a criação de uma nova natureza, mas o fim da Natureza como ordem que legitima a sujeição dos corpos. "Uma análise crítica da diferença de gênero e de sexo, produto do contrato social heterocentrado cujas performatividades normativas foram inscritas nos corpos como verdades biológicas" (Preciado, 2004, p. 21, tradução nossa). Em relação a Foucault, Preciado (2004) tece a noção do corpo como espaço de construção biopolítica. Na perspectiva foucaultiana, compreende-se que dispositivos de poder operam na ordem da disciplina diante 
dos corpos, portanto o sexo seria uma tecnologia biopolítica..$^{10}$ Nesse sentido, estaria a tecnologia social heteronormativa - entendida como conjunto de instituições tanto linguísticas como médicas ou domésticas, que produzem constantemente corpos-homem e corpos-mulher - como uma máquina de produção que funciona mediante a invocação performativa do sujeito como corpo sexuado.

Scott (1995) revisita a visibilidade da experiência para falar da nova história que alcançava a experiência das mulheres, sobretudo na possibilidade da perspectiva social do gênero ser desenvolvida como uma categoria de análise. É o que acontece a partir da segunda metade do século $\mathrm{XX}$, quando Miskolci (2005) explica que o desvio dá lugar às diferenças como categoria de análise diante da forma de questionar os valores que servem como critérios para a invenção do Outro na sociedade. Miskolci (2005) destaca que a sociologia do desvio surge de uma inflexão epistemológica em que a normalidade e o desvio passam pela abordagem das diferenças, sobretudo pelo declínio dos modelos biológicos de identidades sociais. Isso pode ser explicado por Preciado (2004), quando ele destaca que a categoria de homossexual foi uma falha na máquina heterossexual. Por assim dizer, a identidade homossexual seria um acidente sistemático e, logo, estigmatizada como antinatural, abjeta e anormal em benefício às práticas de produção natural da heteronorma. Portanto, porque a heterossexualidade é uma tecnologia social e não uma origem natural fundadora, é possível derivar e inverter suas práticas na produção da identidade sexual.

Variante da sociologia do desvio, a teoria queer surge no final dos anos de 1980 como uma crítica cultural aos estudos de gênero, e não como uma proposta de solução aos problemas abordados nos estudos do corpo; o queer parte de abrir a perspectiva para as noções de heterossexualidade compulsória e da teoria da performatividade frente às práticas e saberes sociais. O termo queer pode ser traduzido do inglês como algo estranho, excêntrico, raro e extraordinário, como explica Louro (2003). As análises queer, com o objetivo de positivar

10 Se pudéssemos chamar de 'bio-história' as pressões por meio das quais os movimentos da vida e os processos da história interferem entre si, deveríamos falar de 'biopolítica' para designar o que faz com que a vida e seus mecanismos entrem no domínio dos cálculos explícitos, e faz do poder-saber um agente de transformação da vida humana. (Foucault, 1988, p. 134). 
a conhecida forma pejorativa de insultar pessoas LGBT $+{ }_{11}^{11}$ buscam desconstruir categorias identitárias através do esmiuçamento dos processos histórico que as criaram. "Gênero e sexualidade são construídos através de inúmeras aprendizagens e práticas, empreendidas por um conjunto inesgotável de instâncias sociais e culturais, de modo explícito ou dissimulado, num processo sempre inacabado" (Louro, 2008, p. 17). Nesse sentido, a perspectiva transviada de Bento (2017) destaca que "um novo corpo conceitual foi acionado para interpretar dimensões da vida tidas como imutáveis, ahistóricas: performance, heteronormatividade, normas de gênero, paródia de gênero, dispositivo da transexualidade, heteroTerrorismo" (Bento, 2014, p. 50).

Na trajetória de Tica existe a formação de guetos, que Simões e França (2005) entendem como lugar de autoaceitação e reconhecimento. É o que se percebe quando Tica fala sobre a brincadeira de esconde-esconde na infância, "que era diferente". "O que chamamos de 'gueto' é algo que só pode ser delimitado ao acompanharmos os deslocamentos dos sujeitos por lugares em que se exercem atividades relacionadas à orientação e a prática homossexual" (Simões; França, 2005, p. 310). Ou seja, lugares que performatizam, por meio itinerante, o desejo. No começo da adolescência de Francisca, a formação dos guetos se inscreve na rua, com os "entendidos" e as "monas". Os pés de juá na Praça Padre Cícero eram espaços de subversão dos desejos e lugar de liberação da performatividade.

A Praça Padre Cícero após as 22 horas se assemelha ao que Butler (2001) chama de "zonas invisíveis e inabitáveis", onde estão os corpos que não "importam" ao mesmo tempo que sofrem opressão, são pontos de resistência. "Paradoxalmente, é ali também que seus corpos se tornam 'materializáveis' e assim disciplináveis" (Miskolci; Pelúcio, 2007, p. 262). Nesse sentido, é possível tecer a noção de corpo abjeto que designa o lugar em que demarca "pessoas que não gozam do estatuto de humanos e, por isso, podem ser violentadas" (Colling, 2015, p. 125).

Quando Tica se assume como homossexual, há uma primeira ruptura. A identificação com a categoria acontece como forma de sair de um possível armário e ter a possibilidade de reivindicar uma identidade ou identidade

11 LGBT+ é a sigla de Lésbicas, Gays, Bissexuais, Travestis, Transexuais ou Transgêneros. O sinal positivo é utilizado para alcançar uma amplitude maior diante do movimento LGBT e ativismos queer. 
alguma. Pois, como pontua Sedgwick (2007), o armário gay não é uma característica apenas das vidas de pessoas gays. $\mathrm{O}$ armário é tido como "dispositivo de regulação da vida de gays e lésbicas que concerne, também, aos heterossexuais e seus privilégios de visibilidade e hegemonia de valores" (Sedgwick, 2007, p. 19). Aos 18 anos, Tica sente vontade de transicionar de sexo, mas não concretiza o procedimento. Como destaca Bento (2014), a experiência transexual revela traços estruturantes das verdades para gêneros, para as sexualidades e para as subjetividades. Desmistificando o saber/poder médico, o qual afirma que as pessoas transexuais têm uma completa abjeção em relação aos seus corpos, Tica convive há 55 anos com um pênis e, segundo ela, "isso não a faz menos mulher". Por estar na meia-idade, Tica já supera a expectativa de vida das pessoas transexuais no Brasil, que segundo dados do Instituto Brasileiro de Geografia e Estatística (IBGE) é de 35 anos.

O encontro de Tica com os Reisados possibilita uma queerização da cultura popular. O ativismo queer volta-se contra a legislação não voluntária da identidade e, nesse sentido, busca desvelar os mecanismos sociais que estabelecem imposições identitárias. O que o difere, como aponta Colling (2015, p. 240), do movimento LGBT, que, "através da afirmação de identidades, tenta forçar todas as pessoas não heterossexuais e não cisgênero a se enquadrar em uma das identidades do LGBT". Logo, Tica abre uma perspectiva transviada para dentro da produção de corpo na narrativa do folguedo do Reisado no grupo Santa Helena. No figural de Rainha, Tica imita o gênero feminino

Ao dizer que o gênero não é só performativo, como também prostético, por se dar na materialidade dos corpos, Preciado (2004) entende a identidade sexual como um efeito de reinserção das práticas de gênero no corpo. Um exemplo disso é quando Tica veste o vestido branco do figural de Rainha na comemoração de oito anos de casamento e diz se sentir no dia das apresentações do Reisado na rua. "O ato de pôr uma roupa, escolher uma cor, acessórios, o corte de cabelo, a forma de andar, enfim, a estética e a estilística corporal, são atos que fazem o gênero, que visibilizam e estabilizam os corpos na ordem dicotomizada dos gêneros" (Bento, 2014, p. 60).

Assim, o papel que os figurais do Reisado inscrevem no corpo dos brincantes faz com que Tica vá além do corpo-mulher e imite a performance na rua como um espaço em que a dissidência sexual e de gênero é produzida no corpo, ou seja, em simulacro. 
É a habilidade para fazer com que a personagem pareça crível para produzir o efeito naturalizado. Esse efeito é, em si mesmo, o resultado de uma corporificação de normas, uma reiteração de normas, uma encarnação da norma racial e de classe que é, por sua vez, a figura de um corpo que não é nenhum corpo em particular, e também o ideal morfológico que continua sendo o modelo que regula a atuação, mas de que nenhuma atuação pode aproximar-se. Significativamente, essa é uma representação que surte efeito, que produz o efeito de autenticidade, na medida em que não pode ler-se. Porque a "leitura" significa degradar alguém, expor o que não funciona no nível da aparência, insultar ou ridicularizar alguém. (Butler, 1993 p. 129, tradução nossa).

Ao aprender epistemologicamente com as práticas culturais e manifestações populares, se entende por que os estudos transviados na análise da performance da brincante desenvolvem agenciamentos localizados através da materialidade performativa. Com isso, a teoria consubstancialidade das relações sociais, desenvolvida por Kergoat (2010), aponta a interdependência dos conflitos de classe, de gênero e raciais. A posição de enunciação de Tica não só é marcada pela performance, mas também por uma estrutura econômica condicionada a uma classe social que demarca o corpo.

De acordo com Kergoat (2010), para compreender de maneira não mecânica as práticas sociais de homens e de mulheres frente à divisão do trabalho é necessário pensar sob o prisma do conceito de consubstancialidade e coextensividade. A autora destaca que as relações sociais são consubstanciais e coexistenciais, sobretudo, porque "as relações sociais de classe, gênero e 'raça' se reproduzem e se co-produzem" (Kergoat, 2010, p. 94). Assim, a análise antropológica de Tica à luz dos estudos transviados permite desatar os nós das práticas sociais que se originam na resistência da tradição. Nesse sentido, em Tica as práticas sociais contestam as relações sociais. "São as práticas sociais - e não as relações intersubjetivas - que podem dar origem a formas de resistência e que podem, portanto, ser portadoras de um potencial de mudança no nível nas relações sociais" (Kergoat, 2010, p. 95).

Na perspectiva da consubstancialidade é possível pensar que não é por ser transexual que Tica desempenha um papel subversivo, mas sim por imitar a Rainha e coletivizar a produção de sentido no simulacro do Reisado, principalmente por se transformar em um sujeito coletivo produtor de sentido. 
Kergoat (2010) lembra que a subversão só pesa sobre as relações sociais se for coletiva e nesse ponto é possível retomar o entendimento de Barroso (2017) a respeito do rido do brincante no Nordeste e o seu caráter coletivo. "Destaca-se que o riso brincante é, principalmente, um riso coletivo. Um riso que se engendra em comunidade, que nasce da embriaguez comum, das relações íntimas e do contato corporal, entre brincantes e comunidade" (Barroso, 2017, p. 242).

Portanto, as relações a partir da performatividade na leitura de gênero passam pelo viés de classes populares, por vezes, não abordadas ou secundarizadas no contexto queer. É nesse sentido que o pensamento transviado invade a produção cultural no Reisado, ao realizar o movimento autorreflexivo e contínuo onde há resistência das realidades analisadas. Afinal, "a potência da teoria queer e seu não congelamento em teorias prévias e sem conexões com as histórias locais dependerá de sua capacidade de absorver essas experiências outras" (Pereira, 2012, p. 389).

Assim, a cultura popular e o folguedo do Reisado inventam novas formas de estar no mundo, atravessadas por noções de que o corpo é pensado na performance cênica da rua.

Há um tipo de agência que não se assemelha às ações reivindicatórias da linguagem dos movimentos sociais, mas que se envolve com determinadas formas de conhecimento e de fazer religioso, com mitologia e performances rituais, com teoria e códigos religiosos. (Pereira, 2012, p. 385).

Tica busca estabelecer uma relação com o Reisado, como se ser Rainha e ocupar um figural feminino justificasse sua sexualidade e sua própria feminilidade, assim como pontua Pereira (2012), ao citar as travestis e a sua relação com os santos de cabeça, para pensar a mitologia dos orixás, para pensar as transformações corporais e os desejos.

Tica sai de um espaço em que seu corpo é abjeto para outro em que seu corpo é legítimo. O figural de Rainha seria para Tica "tão mediador quanto a biotecnologia" (Pereira, 2012, p. 388). Nesse contexto, o seu corpo parece atravessar o espaço público com o artivismo e a devoção. Pelúcio (2012, p. 412) ao desmontar fronteiras sobre a produção de corpos, diz que não se pode esquecer de pensar nossas peculiaridades locais, por isso explica que 
na geografia anatomizada do mundo, nós nos referimos muitas vezes ao nosso lugar de origem como sendo "cu do mundo", ou a fomos sistematicamente localizando nesses confins periféricos e, de certa forma, acabamos reconhecendo essa geografia como legítima. E se o mundo tem cu é porque tem também uma cabeça. Uma cabeça pensante, que fica cima, ao norte, como convêm às cabeças.

Desse modo, apontamos que a performance de Tica como Rainha está próxima dos artivismos das dissidências sexuais e de gênero, nos termos de Colling (2018), e reflete uma produção própria do corpo a partir do contexto cultural na qual foi criado, ou seja, cogita que "os corpos são sucessiva e insistentemente afetados por instâncias, entidades, dispositivos e surgem como novas ontologias, novas formas de estar no mundo, novas formas de participação" (Pereira, 2017, p. 158). A poética do cotidiano de Tica se desvela na incorporação da Rainha na estética do Reisado.

A partir do pensamento de Mauss (1974) é possível dizer que Tica faz uma "imitação prestigiosa", pois como indivíduo a brincante dentro da cultura constrói seu corpo, sobretudo, através das crenças e das tradições. A prática da dança de Reisado aparece como meio para a construção cultural do corpo. Reflete-se na possibilidade de o figural de Rainha, por meio do comportamento e dos usos do corpo, surgir na prática cultural de Tica como a imitação prestigiosa de uma performatividade feminina. Desse modo, a performatividade de Tica na performance como Rainha parece estar "entre 'fazer o corpo' e 'entregar o corpo', usar 'encorporar', com o sentido de materializar, construir, edificar, engendrar (trazer à existência) o corpo" (Pereira, 2017, p. 157).

\section{O percurso dançado, as invenções em cena}

Caracterizadas por serem substantivos femininos, as palavras "cidade" e "mulher" parecem estar indissociadas, mas ao longo da história outra palavra também da derivação substantiva feminina se aproxima mais da noção de feminino: "casa". Apesar da casa estar dentro da cidade e ambas possuírem idiossincrasias complementares, a análise esmiuçada neste trabalho percorre os cômodos de dentro para fora, no intuito de compreender a relação entre o corpo feminino e o espaço urbano. A noção de cidade, pensada e construída por 
homens, que durante séculos confinaram mulheres no espaço doméstico, como articula a abordagem de Risério (2015) sobre a tríade mulher, casa e cidade, aparece neste texto atravessada pela poética do cotidiano e pelo artivismo.

Risério (2015) discute a cidade como artifício humano que implica a vida conversável. A cidade, na abordagem presente, faz-se, em um primeiro momento, ao considerar a performance do Reisado na cultura popular regional como linguagem artística. Assim, busca compreender o espaço que o feminino, interpelado pela imitação performativa de Tica durante a encenação da tradição popular, ocupa na vida comum e na dinâmica conversável da cidade. $\mathrm{O}$ ato de conversar expressa uma cotidianidade que dentro da manifestação do Reisado se desdobra nos pequenos esquetes improvisados pelos grupos da dança. O conversável faz um diálogo com Barroso (2013) através da noção de teatro como encantamento durante o rito do Reisado.

Na abordagem de Barroso (2013), o Reisado pertence ao segmento da população que não escolhe serviço, portanto os brincantes aparecem inseridos em um extrato subalterno da população em que se refletem os acessos da cidade. No grupo Santa Helena, os brincantes vivem de reciclagem, de agricultura e das leis de incentivo à cultura fomentadas pela Secretaria de Cultura (Secult). Desse modo, inseridos na tessitura da cidade, esses grupos de Reisado, ao se visibilizarem nas apresentações, ocupam o lugar entre o público e privado, o que se pode chamar de um lugar visto como fora constitutivo. O corpo, como suporte da voz, dentro desse "entre lugar" que se constitui por meio da aparição, surge através de dois atos, o ato constitutivo e o ato performativo. $\mathrm{Na}$ lógica de Butler (2018), isso seria pensar uma performance construída pela cooperação de dois atos. Portanto, as aparições desses grupos de Reisado testam o funcionamento do limite, o que leva à noção de precariedade aliada à performatividade.

Desfazendo-se do pensamento de Gilberto Freyre sobre os negros escravizados que fugiam para as cidades, Risério (2015) destaca que distante do paradoxo vivido pelo êxodo do campo para a vida nas cidades, o papel do negro, apesar da condição degradante, também gozou da liberdade. Assim, destaca-se o cenário do Reisado que também pode ser contextualizado pela presença da população negra que saiu, em grande parte, dos sítios nas zonas rurais para as expressões das comunidades periféricas nos centros urbanos. "Mil vezes ser malandro do cais, capoeirista abrindo caminhos para os desfiles das 
bandas de Recife, do que encher a pança na senzala de um engenho" (Risério, 2015, p. 25). O contraponto que Risério (2015) faz com Freyre propõe uma reflexão a partir do olhar da cidade a respeito da sociabilidade e da alegria, atravessada também pela performance do Reisado no riso do brincante (Barroso, 2017). Logo, a recriação estética da cidade passaria pela pluralidade da reação desses corpos que se fazem pela ação dos atos na encenação popular.

Corpos, inseridos em um recorte de região, borrariam as leis por meio da tradição. Através do pensamento de Butler (2018) sobre o eixo entre performatividade e precariedade, pode-se dizer que a constituição dos atos do enredo no Reisado, desde o ato de sair da casa e até o ato de aparecer na rua através de apresentações, enuncia uma política de coligação. Nos entrelaçamentos entre a tradição do Reisado e os acessos à cidade, estaria interpelada a noção de alianças brincantes que os corpos dissidentes performatizam no espaço público por meio do teatro encantado da dança religiosa. Portanto, a performatividade dos corpos brincantes na rua cria uma esfera de aparecimento em que designam a territorialidade. $\mathrm{O}$ recorte regionalista toca na religiosidade de Juazeiro do Norte. Desse modo, consideramos que a região, para Albuquerque Junior (2008), alcança uma territorialidade de "comando, domínio e poder", e alça, sob uma perspectiva de soberania, operações estratégicas vinculadas ao referencial identitário.

A reflexão é tangenciada pela soberania exercida pela imagem de autonomia associada a uma "religião popular", como aparece nas contribuições teóricas de Della Cava (1976) sobre a cidade. Para o autor, o Padre Cícero é fruto de dois movimentos frente aos "tempos de crise nacional, regional e local" (Della Cava, 1976, p. 36). A imagem do santo popular aparece, em um primeiro movimento, dentro do conjunto de transformações econômicas pelas quais passou o vale do Cariri entre 1855 e 1877, desde a expansão da agricultura impulsionada por demandas do mercado internacional até a chegada dos primeiros comerciantes a um pequeno desenvolvimento urbano, e em um segundo movimento surge dos esforços impulsionados no sentido de enquadrar a formação clerical e as devoções populares em um modelo romanizado de catolicismo.

No divisor de águas em que se estabelece a imagem do santo popular como legítimo, faz-se necessário relatar o milagre que se supõe ter ocorrido em Juazeiro do Norte em 1889. Segundo Della Cava (1976), antes da chegada do Padre Cícero, já estava sendo cultivada uma religiosidade heterodoxa e eivada de 
"crendices" e de "superstições". O Milagre da Beata na história da cidade permanece em segundo plano, assim como perpassa a construção da cidade de Juazeiro do Norte, inserida no recorte de região e disposta na ordem da dominação masculina, marcada pela figura do homem sacerdote e legitimada pelo poder institucional da igreja. A imagem da beata Maria de Araújo, descrita por Comblin (2014), como lavadeira, solteira e que residia com o Padre Cícero, é sujeitada por uma estrutura social cristalizada na perspectiva androcêntrica de organização social da cidade. O episódio do milagre aconteceu, pela primeira vez, no dia $1^{\circ}$ de março de 1889 ,

ao receber a comunhão, a beata Maria de Araújo caiu por terra sem nenhuma explicação. No mesmo momento, a hóstia caiu-lhe da boca e ficou no chão. Ora, a hóstia estava tingida de sangue. $\mathrm{O}$ mesmo fato repetiu-se todas as quartas e sextas-feiras de Quaresma e, depois disso, a partir do Domingo de Paixão até o Dia da Ascenção voltou a recorrer 47 vezes. (Comblin, 2014, p. 70).

Risério (2015, p. 40) entende o papel da mulher através "de detalhes práticos do desempenho cotidiano a modos de conduta em ritos sociais". A exemplo da imagética feminina dentro do recorte regional, coube à Beata na história de Juazeiro do Norte habitar, mas não construir. Como pontua Aguiar (2000), "o sistema religioso, portanto, é dominado por homens que estabelecem práticas de controle da sexualidade voltadas para a interdição do acesso e até mesmo da visão do corpo feminino" (Aguiar, 2000, p. 310). Não só na tessitura da cidade, mas também na narrativa cotidiana, a vida de mulheres, como a Beata, inseridas no contexto religioso de Juazeiro do Norte, reflete a precariedade de corpos que possuem validade e são passíveis de luto público. A Beata Maria de Araújo se torna um sujeito produzido para confirmar a norma, no caso, o milagre da benfeitoria do Padre Cícero, estando esquecida e secundarizada pela memória coletiva. Não obstante, a imagética discursiva da regionalidade em Juazeiro do Norte estaria centralizada no significado do Padre Cícero.

A reflexão sobre as práticas subversivas dentro do Reisado e a aparição dos corpos no espaço público durante os cortejos da dança são pertinentes para a análise para se pensar como se aliam e se coligam os corpos ilegíveis ou considerados supérfluos. O Reisado pode ser uma tradição religiosa do catolicismo 
popular dentro do recorte espacial de Juazeiro do Norte, pois a manifestação cultural aparece atravessada pela fé dos brincantes no Padre Cícero. Nesse sentido, como pensar as transgressões performativas de gênero por meio da imitação subversiva de um corpo não em conformidade, lido pela heteronorma ainda hegemônica nas práticas da cultura popular?

Para Barroso (2013) o Reisado é uma caminhada que tem sentido, mas não uma rota determinada. $\mathrm{O}$ agir em coletivo de um grupo de Reisado condiciona o aparecimento de corpos com vozes para compor a narrativa constitutiva da cidade. Os grupos de Reisado compõem uma noção de pertencimento voltada para região, memória e religião. Como exemplo, Barroso (2013) destaca que nas cidades de Canindé e de Juazeiro do Norte, onde se brinca o Reisado em devoção, é reforçada a obrigação de que os filhos dos mestres de folguedos devem sucedê-los na cultura popular.

Principalmente, quando a brincadeira é resultado de uma promessa para São Francisco ou Padre Cícero, o que ocorre com frequência. Apesar de possuir grupos com seguidores de cultos afro-ameríndios e afro-brasileiros, a grande população que brinca Reisado é católica e possui um nome de santo popular católico na tradição. No Reisado Santa Helena, do Mestre Dedé, a santa homenageada vem sendo cultivada pela devoção do pai do Mestre. Logo, o papel da família, desempenhado na perspectiva de dentro para fora, ou seja, da casa para a rua, na estrutura da brincadeira de Reisado é importante para análise. Pois essas famílias

relacionam-se, na maior parte, com estruturas comunais ligadas a determinados locais, geralmente em sítios e pequenos povoados. Marcam laços de convivência e amizade combinados a laços de consanguinidade, valores e formas de organização social herdadas, talvez, tanto de antigas comunidades afro-brasileiras e ameríndias, quanto de corporação de ofícios europeias. (Barroso, 2013, p. 50).

José Amaro da Silva é o mestre do Reisado Santa Helena em Juazeiro do Norte. Morador no bairro Mutirão, ele conta que o grupo atua na cultura popular há mais de 30 anos. Para o Mestre Dedé, o Reisado veio do tempo do menino Deus, assim como na tradição cristã católica. Ao explicar sobre a origem da dança, o Mestre fala sobre o nascimento do menino Jesus, da passagem bíblica em que José e Maria ganham o filho no curral de uma fazenda, da Estrela Dalva, 
e dos três Reis Magos Belchior, Baltasar e Gaspar - mencionados apenas no Evangelho segundo Mateus, onde se afirma que teriam vindo "do leste" para adorar o Cristo, "nascido Rei dos Judeus". Dedé começou a brincar Reisado com o pai no Reisado São Sebastião - que aprendeu com Mané Cordeiro e Mané Cazuza -, e ainda menino ia trabalhar em São Paulo e voltava todo final de ano para tirar quilombos com ele. Hoje com 49 anos, possui seis filhos. Cresceu brincando com Mestre Pedro e Mestra Augusta, e de repente se deu a pensar na construção do seu próprio grupo.

Através da trajetória de Dedé, é possível perceber que a formação das famílias no Reisado aparece pelo viés comunitário, o que pode escapar dos moldes provedores masculinistas, apesar de algumas vezes os grupos aparecerem liderados por um único mestre que passa o comando do brinquedo para os filhos. Assim, Barroso (2013) pontua que a família de brincantes se diferencia da tradicional família patriarcal sertaneja, que é organizada em torno de um chefe absoluto, ou seja, da figura do masculina e rígida do pai. A perspectiva de Risério (2015), de dentro para fora da casa, permite traçar a noção de performance no espaço público. Butler (2016) tece a noção de gêneros inteligíveis em paralelo ao sentido de coerência e de continuidade. Ao retomar o elemento da aparição como deslocador de tensões de gênero, parte-se da premissa de que, apesar das apresentações de Reisado corresponderem às territorialidades e às regionalidades hegemôniccas rituais, possuem um modelo performativo de reprodução da identidade que desmantela a noção de natural.

A performance do grupo de Reisado na rua, ao que percebe Barroso (2013), compõe um cenário caótico, comportando um sem-número de possibilidades, tanto na estrutura dos personagens como na quantidade e na qualidade dos entremezes. Os atos improvisados nas cenas dramáticas do Reisado produzem um efeito de performances repetidas, que no cortejo reatualizam discursos históricos e culturalmente rígidos, como no exemplo da imitação de Tica e do simulacro da Rainha. Ao entender o folguedo como elemento que enuncia a performatividade, é possível dizer que a brincante corporifica repetições que rompem com os contextos normativos de produção de identidades e explicita os mecanismos mesmos de sua produção, sobretudo, ao sobrepor determinada biologia com estilizações específicas do corpo (a linguagem incluída). 
Barroso (2013), ao falar da performance cênica nas apresentações, geralmente realizadas na imersão na vida da comunidade, em rodas e espaços a céu aberto, define, segundo os princípios da cena tradicional, a construção codificada das personagens. Para o autor, os Reisados "utilizam expressões de culturas orais, utilizam linguagens mito-poéticas que, muitas vezes, não privilegiam a palavra no processo de comunicação" (Barroso, 2013, p. 307). Diante disso, a atuação ocorre por meio de hábitos incorporados, principalmente, em um conjunto de quadros autônomos com pequenas encenações baseadas não em uma imitação naturalista do cotidiano, mas em narrativas apoiadas na coletividade, que apresenta evidentemente traços místicos no imaginário social.

A posição dispõe de seis figurais de um lado, seis de outro, a Princesa e a Rainha na frente com o Príncipe e o Rei. Dedé conta que o figural ocupado por Tica é uma invenção sua, "tinha só a Princesa, aí inventei de botar a Rainha". Ao todo são quase 20 brincantes. $O$ embaixador fica no lado esquerdo, e outro embaixador, no lado direito; no meio ficam a Rainha, a Princesa, o mestre e os reis. Antigamente, havia até o contracoice ou contramestre, que tomava o posto do dono do Boi quando o mesmo cansava nas apresentações, e entregava o apito para um segundo, e em seguida para um terceiro, até o mestre recuperar o fôlego. Atrás, o cordão com as figuras. O mestre canta e os figurais repetem. Nas praças, o tempo da apresentação não permite que todos os bichos sejam apresentados. Mas caso todos entrem em cena, Dedé conta que o cortejo dura aproximadamente uma hora.

Para Maffesoli (2001), a cultura contém uma parte do imaginário, mas não se reduz ao imaginário. A cultura é descritiva, o imaginário, imponderável. A aliança desses corpos estariam no entre lugar da cultura e do imaginário. Ao fazer um paralelo com Butler (2016) sobre a identidade performativa, cabe a reflexão do que podem os corpos aliados para além da identificação e quais os efeitos que se desvelam na reapropriação dos discursos de produção do poder/saber. Tica imita o gênero na mesma medida em que subverte a tradição dentro do simulacro da Rainha no Reisado Santa Helena, a performatividade contestadora perpassa as noções de tradição e de cultura popular, ambas ainda pautadas no ideal de cabra macho, como explica Albuquerque Junior (1999), e marcadas pela hegemonia masculina no discurso popular. É possível dizer que a Rainha pode aliar corpos e promover uma reflexão sobre a poética do corpo na dança religiosa. 


\section{Considerações finais}

Nosso último encontro com Tica ocorreu no dia 10 de março de 2019 no bairro Timbaúbas, em Juazeiro do Norte. Era domingo e ela estava em casa com o companheiro. A carroça estava do lado de fora. Aos 55 anos, ela ressaltou que pelo fato de estar mais velha não pode mais brincar como Rainha, e justifica isso ao me mostrar remédios, adquiridos pelo Sistema Único de Saúde (SUS), para combater o seu recente problema de anemia. Tica ainda brincou como embaixador nos cordões do Reisado Santa Helena na última terreirada ${ }^{12}$ que o grupo apresentou, no Ciclo de Reis, entre os meses de novembro de 2018 e janeiro de 2019.

Ao apontar para a televisão de 14 polegadas, a brincante diz que o atual presidente da República, Jair Bolsonaro, fez um comentário homofóbico que saiu dias atrás em um telejornal. Confessa que por conta disso está com receio de se vestir como se vestia antes e sair na rua. Ela conta que recentemente novos vizinhos tiveram a mesma atitude homofóbica que viu nas palavras do presidente. Cícero abaixa a cabeça e diz também sentir muito pelo período político. Apesar de analfabeta, Tica parece estar ciente da atual conjuntura do governo e da ameaça do mesmo às questões de gênero e sexualidade.

\section{Referências}

AGUIAR, N. Patriarcado, sociedade e patrimonialismo. Sociedade e Estado, Brasília, v. 15, n. 2, p. 303-330, jun./dez. 2000.

ALBUQUERQUE JUNIOR, D. M. de. A invenção do Nordeste e outras artes. Recife: Massangana, 1999.

ALBUQUERQUE JUNIOR, D. M. de. O objeto em fuga: algumas reflexões em torno do conceito de região. Fronteiras, Dourados, v. 10, n. 17, p. 55-67, jan./jun. 2008.

BARROSO, O. Teatro como encantamento: bois e reisados de caretas. Fortaleza: Armazém da Cultura, 2013.

12 Tipo de apresentação de Reisado que acontece no terreiro da casa do mestre, espaço localizado da porta para fora, geralmente situado na calçada ou na rua. 
BARROSO, O. O riso brincante do Nordeste. Rebento, São Paulo, n. 7, p. 233-265, dez. 2017.

BENTO, B. O que pode uma teoria? Estudos transviados e a despatologização das identidades trans. Florestan, v. 2, p. 46-66, 2014.

BENTO, B.Transviad@s: gênero, sexualidade e direitos humanos. Salvador: EDUFBA, 2017.

BUTLER, J. Bodies that matter: on the discursive limits of "sex". New York: Routledge, 1993.

BUTLER, J. Corpos que pesam: sobre os limites discursivos do "sexo". In: LOURO, G. L. (org.). O corpo educado: pedagogias da sexualidade. 2. ed. Belo Horizonte: Autêntica, 2001. p. 152-172.

BUTLER, J. Problemas de gênero: feminismo e subversão da identidade. Rio de Janeiro: Civilização Brasileira, 2016.

BUTLER, J. Corpos em aliança e a política das ruas: notas para uma teoria performativa da assembleia. Rio de Janeiro: Civilização Brasileira, 2018.

CARLSON, M. O entrelaçamento dos estudos modernos da performance e as correntes atuais em antropologia. Revista Brasileira de Estudos da Presença = Brazilian Journal on Presence Studies, v. 1, n. 1, p. 164-188, 2011.

CAVALCANTI, M. L. V. de C. Drama, ritual e performance em Victor Turner. Sociologia e Antropologia, v. 3, n. 6, p. 411-440, 2013.

COLLING, L. Que os outros sejam o normal: tensões entre movimento LGBT e ativismo queer. Salvador: EDUFBA, 2015.

COLLING, L. A emergência dos artivismos das dissidências sexuais e de gêneros no Brasil da atualidade. Sala Preta, v. 18, n. 1, p. 152-167, 2018.

COMBLIN, J. Padre Cícero de Juazeiro. São Paulo: Pia Sociedade de São Paulo: Paulus, 2014.

DAWSEY, J. C. Victor Turner e antropologia da experiência. Cadernos de Campo, ano 14, n. 13, p. 110-121, 2005.

DAWSEY, J. C. Turner, Benjamin e antropologia da performance: o lugar olhado (e ouvido) das coisas. Campos, v. 7, n. 2, p. 17-25, 2006 a.

DAWSEY, J. C. O Teatro em Aparecida: a santa e a lobisomem. Mana, v. 12, n. 1, p. 135$150,2006 b$. 
DELLA CAVA, R. Milagre em Joaseiro. Rio de Janeiro: Paz e Terra, 1976.

FOUCAULT, M. História da sexualidade I: a vontade de saber. Rio de Janeiro: Graal, 1988.

GOLDMAN, M. Alteridade e experiência: antropologia e teoria etnográfica. Etnográfica, Lisboa, v. 10, n. 1, p. 161-173, maio 2006.

KERGOAT, D. Dinâmica e consubstancialidade das relações sociais. Novos Estudos CEBRAP, n. 86, p. 93-103, 2010.

LOURO, G. L. Corpos que escapam. Estudos Feministas, v. 4, n. 4, p. 1-7, 2003.

LOURO, G. L. Gênero e sexualidade: pedagogias contemporâneas. Pro-Posições, v. 19, n. 2, p. 17-23, 2008.

MAFFESOLI, M. Michel Maffesoli: o imaginário é uma realidade. Revista Famecos, v. 8, n. 15, p. 74-82, 2001.

MAUSS, M. As técnicas corporais: sociologia e antropologia. São Paulo: EPU: Edusp, 1974.

MISKOLCI, R. Do desvio às diferenças. Teoria e Pesquisa, v. 1, n. 47, p. 9-41, jul./dez. 2005.

MISKOLCI, R.; PELÚCIO, L. Fora do sujeito e fora do lugar: reflexões sobre performatividade a partir de uma etnografia entre travestis. Revista Gênero, Niterói, v. 7, n. 2, p. 257-269, 1. sem. 2007.

OLIVEIRA, R. C. de. O trabalho do antropólogo: olhar, ouvir, escrever. In: OLIVEIRA, R. C. de. O trabalho do antropólogo. São Paulo: Paralelo 15: Unesp, 1988. p. 17-36.

OLIVEIRA, R. J. de; FORTES, L. O tempo de exceção do riso no reisado: a cartografia da performance de brincantes transviados e o terreiro do mestre como espaço educativo. Diversidade e Educação, v. 6, n. 2, p. 53-61, 2018.

OLIVEIRA JUNIOR, R. J. de. Tica nasceu de papo para cima: enunciados performativos na rainha do Reisado Santa Helena. Cadernos Pagu, Campinas, n. 55, e195523, 2019. Disponível em: http://www.scielo.br/scielo.php?script=sci_arttext\&pid=S0104-83332019000100512\&lng=pt\&nrm=iso. Acesso: 15 jul. 2019.

PEIRANO, M. Etnografia não é método. Horizontes Antropológicos, Porto Alegre, ano 20, n. 42, p. 377-391, dez. 2014.

PELÚCIO, L. Subalterno quem, cara pálida? Apontamentos às margens sobre pós-colonialismos, feminismos e estudos queer. Contemporânea, v. 2, n. 2, p. 395-418, 2012. 
PEREIRA, P. P. G. Queer nos trópicos. Contemporânea, v. 2, n. 2, p. 371-394, 2012.

PEREIRA, P. P. G. As incorporações e suas poéticas. Debates do NER, Porto Alegre, ano 18, n. 31, p. 137-171, jan./jun. 2017.

PRECIADO, B. Manifiesto contrasexual. Barcelona: Anagrama, 2004.

RISÉRIO, A. Mulher, casa e cidade. São Paulo: Editora 34, 2015.

ROHDEN, F.; RUSSO, J. A.; ROCA, A. Apresentação. Horizontes Antropológicos, Porto Alegre, ano 23, n. 47, p. 9-26, jan./abr. 2017.

SCHECHNER, R. Drama, script, theatre and performance. The Drama Review, New York, v. 17, n. 3, p. 5-36, Sept. 1973.

SCHECHNER, R. Selective inattention: a traditional way of spectating now part of the avant-garde. Performing Arts Journal, Baltimore, v. 1, n. 1, p. 8-19, Spring 1976.

SCOTT, J. W. Gênero: uma categoria útil de análise histórica. Educação e Realidade, Porto Alegre, v. 20, n. 2, p. 71-99, jul./dez. 1995.

SEDGWICK, E. K. A epistemologia do armário. Cadernos Pagu, n. 28, p. 19-54, 2007.

SIMÕES, J. A.; FRANÇA, I. L. Do "gueto" ao mercado. In: GREEN, J. N.; TRINDADE, R. (org.). Homossexualismo em São Paulo e outros escritos. São Paulo: Editora Unesp, 2005. p. 309-336.

TURNER, V. Liminality and communitas. In: TURNER, V. The ritual process: structure and anti-structure. New York: Cornell University Press, 1969. p. 94-130.

TURNER, V. Introduction. In: TURNER, V. From ritual to theatre: the human seriousness of play. New York: PAJ, 1982. p. 7-19.

TURNER, V. The anthropology of performance. In: TURNER, V. The anthropology of performance. New York: PAJ, 1987. p. 72-98.

TURNER, V. Dewey, Dilthey, e drama: um ensaio em antropologia da experiência. Cadernos de Campo, São Paulo, ano 14, n. 13, p. 177-186, 2005.

TURNER, V. Liminal ao liminoide: em brincadeira, fluxo e ritual-um ensaio de simbologia comparativa. Mediações, v. 17, n. 2, p. 214-257, 2012.

Recebido: 11/03/2019 Aceito: 24/06/2019 | Received: 3/11/2019 Accepted:6/24/2019 